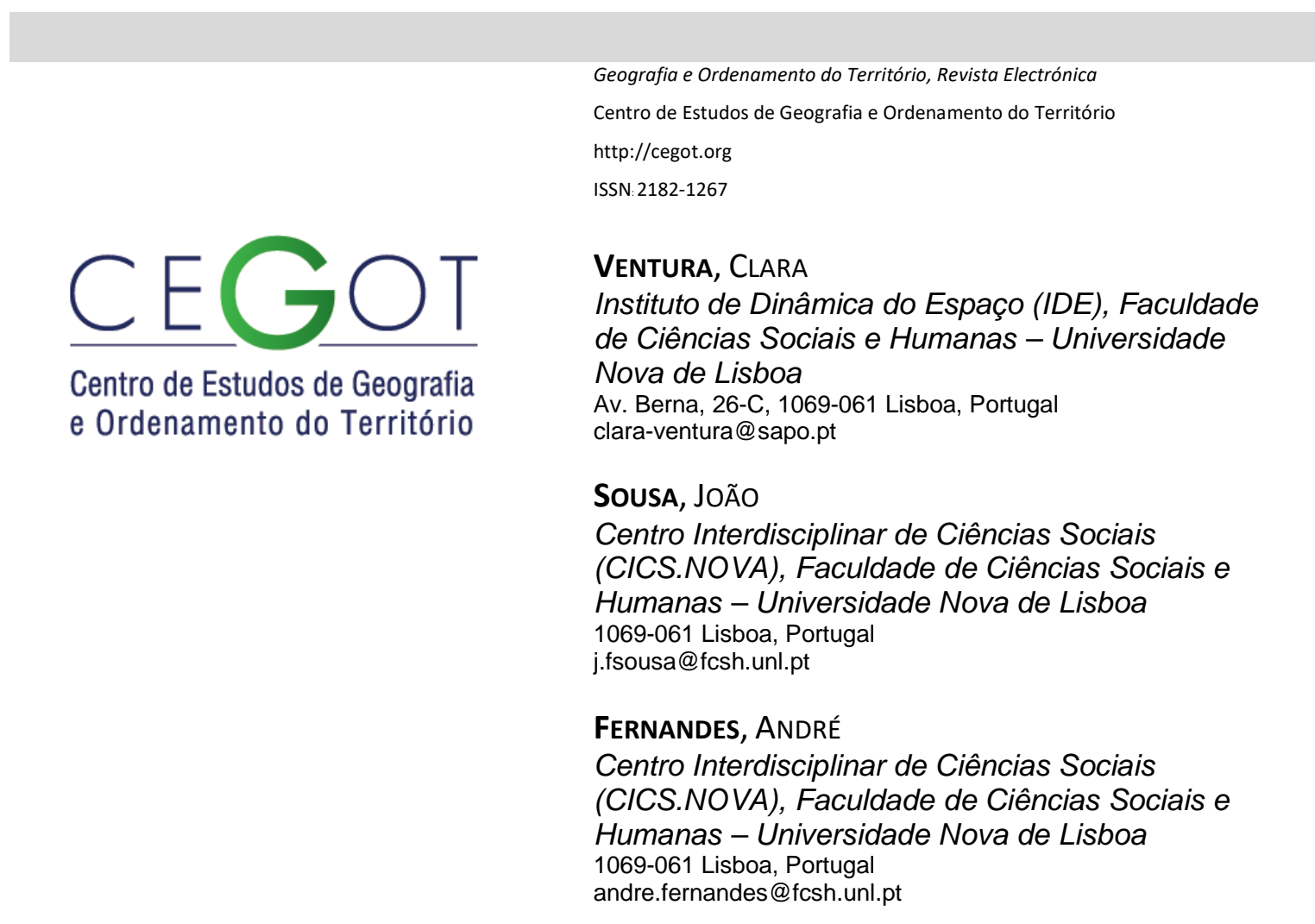

\title{
Os estuários e as alterações climáticas: impactes da subida do nível médio das águas do mar em Vila Franca de Xira
}

Estuaries and climate change: impacts of sea level rise in Vila Franca de Xira

Referência: Ventura, Clara; Sousa, João; Fernandes, André (2017). Os estuários e as alterações climáticas: impactes da subida do nível médio das águas do mar em Vila Franca de Xira. Revista de Geografia e Ordenamento do Território (GOT), n.o 11 (junho). Centro de Estudos de Geografia e Ordenamento do Território, p. 327-350, dx.doi.org/10.17127/got/2017.11.015

\section{RESUMO}

A subida do nível médio do mar é uma das consequências da emissão antropogénica de gases com efeito de estufa, afetando particularmente as zonas costeiras e estuarinas. Neste contexto, o artigo aborda a problemática da subida do nível médio do mar tendo como caso de estudo a frente ribeirinha do concelho de Vila Franca de Xira. Adota-se a abordagem what if, tendo como cenário de referência no horizonte 2100 uma subida do nível médio do mar até ao tipping point de 4,5 metros. São avaliados os impactes sobre a população residente, $o$ edificado $e$ as principais infraestruturas de transporte que existem presentemente nesta frente ribeirinha.

Palavras-chave: alterações climáticas, subida do nível médio do mar, cenários, inundações, frentes ribeirinhas. 


\section{ABSTRACT}

The mean sea level rise is one of the consequences of anthropogenic greenhouse gas emissions and affects particularly coastal and estuarine areas. In this context, the article addresses the problem of mean sea level rise taking as a case study the riverfront of Vila Franca de Xira municipality. It is adopted the "what if" approach, having as reference scenario on the horizon 2100 the mean sea level rise to the tipping point of 4,5 meters. The article assesses the impacts on resident population, buildings and main transportation infrastructures that presently exist in this riverfront.

Keywords: climate change, mean sea level rise, scenarios, floods, riverfronts.

\section{Introdução}

As zonas costeiras, nas quais se inserem as áreas estuarinas, destacam-se, de um modo geral, pelas elevadas densidade populacional e concentração de atividades económicas, pela diversidade e sensibilidade dos ecossistemas e pela complexidade de usos e funções resultante da atratividade que têm vindo a exercer ao longo do tempo, mercê de fatores vários (Fernandes, 2014). Estas áreas estão igualmente sujeitas a uma grande pressão devido à contínua exploração dos recursos aqui existentes, aspeto que se traduziu em sucessivas alterações nos usos das suas margens e plano de água.

Neste contexto, a subida do nível médio do mar (NMM), que constitui uma das consequências das alterações climáticas, vem contribuir para o aumento da pressão a que estes territórios já estão sujeitos.

Dados maregráficos e, mais recentemente, também dados resultantes de altimetria por satélite mostram que o NMM tem vindo a subir na maioria das regiões do planeta. Segundo o IPCC - Intergovernmental Panel on Climate Change (2013), o NMM global subiu 0,19 m no período 1901-2010. Têm vindo ainda a ser desenvolvidos vários modelos climáticos que preveem a continuação daquela subida de forma mais ou menos acentuada. Por exemplo, Church et al. (2013) apresentam, com base em modelos geofísicos, projeções da subida do NMM entre 0,19 e 0,83 m para o horizonte temporal 2100, enquanto Vermeer e Rahmstorf (2009), utilizando uma abordagem semi-empírica, apresentam projeções da subida do NMM entre 0,75 e 1,90 m para o mesmo período. Para a Região de Lisboa, Antunes et al. (2013), com base em dados do marégrafo de Cascais, projetam uma subida do NMM de 0,95 m 
(valor central) para o período 2000-2100. Desta forma, a subida do NMM pode implicar a submersão permanente ou ocasional de zonas costeiras, afetando atividades humanas e os sistemas naturais.

No caso específico das áreas estuarinas, estas estão sujeitas à influência marítima e fluvial, sendo que a combinação da subida do NMM com eventos climáticos extremos, como por exemplo precipitação intensa, faz com que sejam territórios cada vez mais vulneráveis a inundações. É neste contexto que releva a avaliação dos impactes da subida do NMM no Estuário do Tejo, assim como a definição de estratégias de adaptação a nível regional e municipal, passíveis de transposição para os instrumentos de gestão territorial, numa ótica de planeamento e gestão integrados.

Note-se que segundo Figueira de Sousa et al. (2013), a vulnerabilidade a inundações no Estuário do Tejo não é similar em todo o território, existindo áreas com maior vulnerabilidade, como são os casos de Alhandra e Vila Franca de Xira, que se apresentam mais vulneráveis a inundações que Lisboa. Algo que, de acordo com estes autores, se verifica principalmente nas áreas de baixa altitude, quando marés altas e eventos climáticos se combinam.

Neste contexto, o artigo pretende avaliar e discutir os impactes resultantes da subida do NMM sobre a população residente, o edificado e as principais infraestruturas de transporte na frente ribeirinha do concelho de Vila Franca de Xira, considerando cenários de alterações climáticas para o horizonte temporal de 2100.

Para tal, efetuou-se uma simulação da subida do NMM com base num Modelo Digital do Terreno (MDT) e adotando a abordagem what if, considerando um tipping point de 4,5 m. Um valor de referência para o planeamento urbano na cidade de Lisboa num contexto de alterações climáticas, proposto e adotado pelo Projeto de Investigação "Estuários e Deltas Urbanizados. Contributos para um Planeamento e Gestão Integrados. O Caso de Lisboa" (2010-2013), no âmbito do qual o presente artigo se enquadra.

\section{Problematização - As alterações climáticas e a subida do NMM}


A utilização de dados meteorológicos, principalmente dos séculos $\mathrm{XIX}$ e $\mathrm{XX}$, tem permitido constatar várias alterações do clima, bem como realizar projeções. De um modo geral, os estudos climáticos que foram desenvolvidos permitiram concluir que a temperatura média do planeta tem vindo a aumentar desde o início dos registos globais, em 1850. Tal facto é uma consequência do aumento das concentrações de gases com efeito de estufa (GEE) e, bem assim, da intensificação do efeito de estufa.

Por outro lado, segundo o IPCC (2013), a partir da segunda metade do século XX têm-se observado alterações nos extremos de fenómenos climáticos. É ainda afirmado por esta mesma fonte, com uma probabilidade de $66-100 \%$, que as chuvas torrenciais aumentaram em muitas regiões do planeta e que níveis do mar extremos (como aqueles observados em storm surges) aumentaram desde 1970, resultando principalmente da subida do NMM.

Especificamente no que se refere ao oceano, importa ter presente que este absorve mais de 93\% do excesso de calor retido na superfície terrestre devido ao aumento das concentrações atmosféricas de GEE (WMO - World Meteorological Organization, 2015). A absorção da maior parte do excesso de calor por este elemento provoca, naturalmente, o aquecimento das suas camadas superiores (que já foi observado até aos $2000 \mathrm{~m}$ de profundidade). Entre 1971 e 2010 registou-se um aquecimento superior a $0,1{ }^{\circ} \mathrm{C}$ por década até à profundidade de 75 m (Santos, 2013). Ora, o aumento da temperatura dos oceanos provoca a subida do NMM, que ocorre por meio de dois processos: expansão térmica das camadas superiores dos oceanos, que segundo o IPCC (2013), é responsável por mais de 70\% da subida do NMM; e adição de água proveniente do degelo dos glaciares continentais e das calotes polares. No período de 1901 a 2010, o NMM subiu 0,19 m, tendo sido a sua subida média anual de 1,7 mm (IPCC, 2013). Para o período de 1993 a 2010 a estimativa da subida média anual do NMM está compreendida entre 2,8 e 3,6 mm (IPCC, 2013).

Conclui-se, assim, que o aumento do NMM não tem sido uniforme ao longo do tempo, sendo superior nas últimas décadas. Por outro lado, há que ter presente que o NMM também não é espacialmente uniforme. Segundo Santos (2013), o NMM depende do nível local do oceano em relação ao centro da Terra. O nível local do oceano varia com as tempestades e com a variabilidade climática, sendo que esta causa alterações nos ventos à 
superfície do oceano, nas correntes oceânicas, na temperatura e na salinidade da água (Santos, 2013).

Desta forma, para efetuar simulações da subida do NMM e posteriormente avaliar os seus impactes sobre os sistemas humanos e naturais, é necessário considerar cenários que tenham em conta o nível local médio do mar e as respetivas projeções de subida.

Para a costa continental portuguesa, os registos maregráficos permitiram estimar uma subida do NMM de cerca de 0,1 m a 0,2 $\mathrm{m}$ durante o século $X X$, sendo que no marégrafo de Cascais, a taxa de subida anual no período 1920-1987 foi de 1,7 mm (Santos et al., 2001). Antunes (2013) apresenta, uma taxa de subida do NMM em Cascais de 1,9 mm/ano para o período 1920-2000 e uma taxa de 3,6 mm/ano para o período 2000-2010. Verifica-se, assim, que os valores da subida do NMM obtidos para Portugal e Cascais aproximam-se da média global.

Num horizonte de muito longo prazo, os modelos baseados em processos geofísicos apresentados pelo IPCC projetam, para o período 2081-2100 (relativamente a 1986-2005), uma subida do NMM entre 0,26 m e 0,55 m, no caso do melhor cenário de emissões de GEE (RCP 2,6) e uma subida entre $0,45 \mathrm{~m}$ e $0,82 \mathrm{~m}$, no caso do pior cenário (RCP 8,5), correspondente ao maior volume de emissões de GEE (IPCC, 2013).

Jevrejeva et al. (2012), utilizando também um modelo geofísico, apresentam para o ano 2100, as seguintes projeções de subida do NMM: 0,57 m, considerando o cenário RCP 2,6; 1,10 m, considerando o cenário RCP 8,5.

No entanto, os modelos semi-empíricos produzem, em geral, estimativas superiores. Por exemplo, Rahmstorf (2010) afirma que as projeções do IPCC subestimam a subida do NMM e apresenta uma projeção de 1,14 m para 2095 e de 1,24 m para 2100 utilizando modelos semi-empíricos. Ainda assim, o mesmo autor alerta para a incerteza inerente às previsões efetuadas pelos modelos semi-empíricos e para a dificuldade em prever a resposta do sistema climático ao aumento da temperatura. Refere ainda que os modelos semi-empíricos reproduzem muito bem a subida do NMM no passado (ao contrário dos modelos geofísicos), embora estejam limitados na medida em que não há forma de assegurar se a 
relação entre a subida do NMM e a temperatura verificada no passado vai continuar a manter-se no futuro (Rahmstorf, 2010).

No que respeita ao caso português, mais especificamente para a Região Hidrográfica do Tejo, Antunes et al. (2013), efetuaram um estudo no qual projetam o valor central de 0,95 m para a subida do NMM no período 2000-2100. Tal estimativa foi obtida com base em modelos empíricos, por extrapolação dos valores de subida e de aceleração do NMM calculados para o período 1991-2010 no marégrafo de Cascais (Antunes et al., 2013). Tendo em conta aquele resultado e as projeções para a subida do NMM global, os autores apresentam 2 cenários de subida do NMM: um cenário mais otimista correspondente a uma subida de 0,50 m, em concordância com as projeções do IPCC; um cenário extremo correspondente a uma subida de 1,50 m, em concordância com as "recomendações da generalidade da comunidade científica como adequado para efeitos de ordenamento e gestão do risco da zona costeira" (Antunes et al., 2013).

Além dos valores projetados nas técnicas de modelação, há ainda que considerar algumas agravantes. Uma delas é a inércia térmica do oceano, que faz com que o NMM continue a subir mesmo que as emissões antropogénicas de GEE diminuam acentuadamente. A este respeito, Jevrejeva et al. (2012) preveem que o NMM continue a subir durante vários séculos mesmo depois da estabilização das emissões de GEE, com maior taxa de subida depois de 2100 devido à inércia térmica do oceano. Outra agravante é a incerteza em relação ao comportamento perante o aquecimento global por parte das massas de gelo da Gronelândia e, principalmente, do setor Oeste da Antártica (situada abaixo do NMM), pois são consideradas menos estáveis (Santos, 2013; IPCC, 2013).

Tais dados são particularmente relevantes num contexto em que cerca de metade da população mundial vive a menos de $60 \mathrm{~km}$ da linha de costa, acrescendo que, segundo Santos (2013), cerca de um terço da linha de costa mundial é constituída por estuários, deltas, praias, dunas e ilhas barreira, que são sistemas dinâmicos de potencial residencial, recreativo e turístico. Note-se que a ocorrência de eventos climáticos extremos pode ter vários efeitos nas zonas costeiras de baixa altitude, destacando-se os impactes potenciais associados ao fenómeno de storm surge. A combinação da subida do NMM com este 
fenómeno, eventos de maré alta, ondulação forte ou precipitação forte contribui para o aumento do risco de inundações nas zonas costeiras de baixa altitude.

No caso específico dos estuários, estes possuem a dinâmica e a complexidade característica das zonas costeiras e, como parte integrante delas, são afetados pelos mesmos fenómenos climáticos e sofrem impactes comuns. No entanto, as alterações climáticas podem ter aqui consequências mais gravosas devido às suas especificidades e à interação de fatores não climáticos. As áreas de estuário apresentam-se, geralmente, como áreas planas e sujeitas à influência marítima e fluvial, tendo assim os seus elementos expostos a todo o tipo de inundações. O aumento do NMM coloca por isso os estuários em elevado risco de inundações costeiras, submersão permanente, cheias, erosão, intrusão salina e perda de zonas húmidas (Mendes e Oliveira, 2013). Acresce que, nas zonas costeiras urbanizadas de baixa altitude, o risco de prejuízos relacionados com inundações está a aumentar devido ao crescimento populacional que continua a verificar-se nestas zonas, à exposição da propriedade e à ocupação urbana de zonas vulneráveis, como aquelas suscetíveis ao recuo da linha de costa (Santos, 2013). Algo tanto mais relevante quanto, a longo prazo, os cenários apontam para um aumento do risco de inundações permanentes de zonas costeiras de baixa altitude, devido à subida do NMM, com a consequente destruição do património, infraestruturas e estruturas portuárias (Santos, 2013). Além disso, tal situação leva à perda permanente de solo e à salinização dos recursos hídricos, coloca desafios ao planeamento do território, acarreta problemas para o funcionamento do sistema de transportes e causa prejuízos em sectores como o turismo, a agricultura e as pescas.

\section{Impactes potenciais da subida do NMM na frente ribeirinha de}

\section{Vila Franca de Xira}

\subsection{Metodologia e cenários de subida do NMM no Estuário do Tejo}

A adaptação à subida do NMM e a promoção da resiliência dos territórios ribeirinhos requer a avaliação do risco de inundações resultante de cheias, como também das vulnerabilidades destes territórios. No caso do concelho de Vila Franca de Xira, as vulnerabilidades atuais 
têm particular incidência na sua frente ribeirinha de baixa altitude (localizada no prolongamento para norte da frente ribeirinha de Lisboa), confinante com o plano de água estuarino (Figura 1).

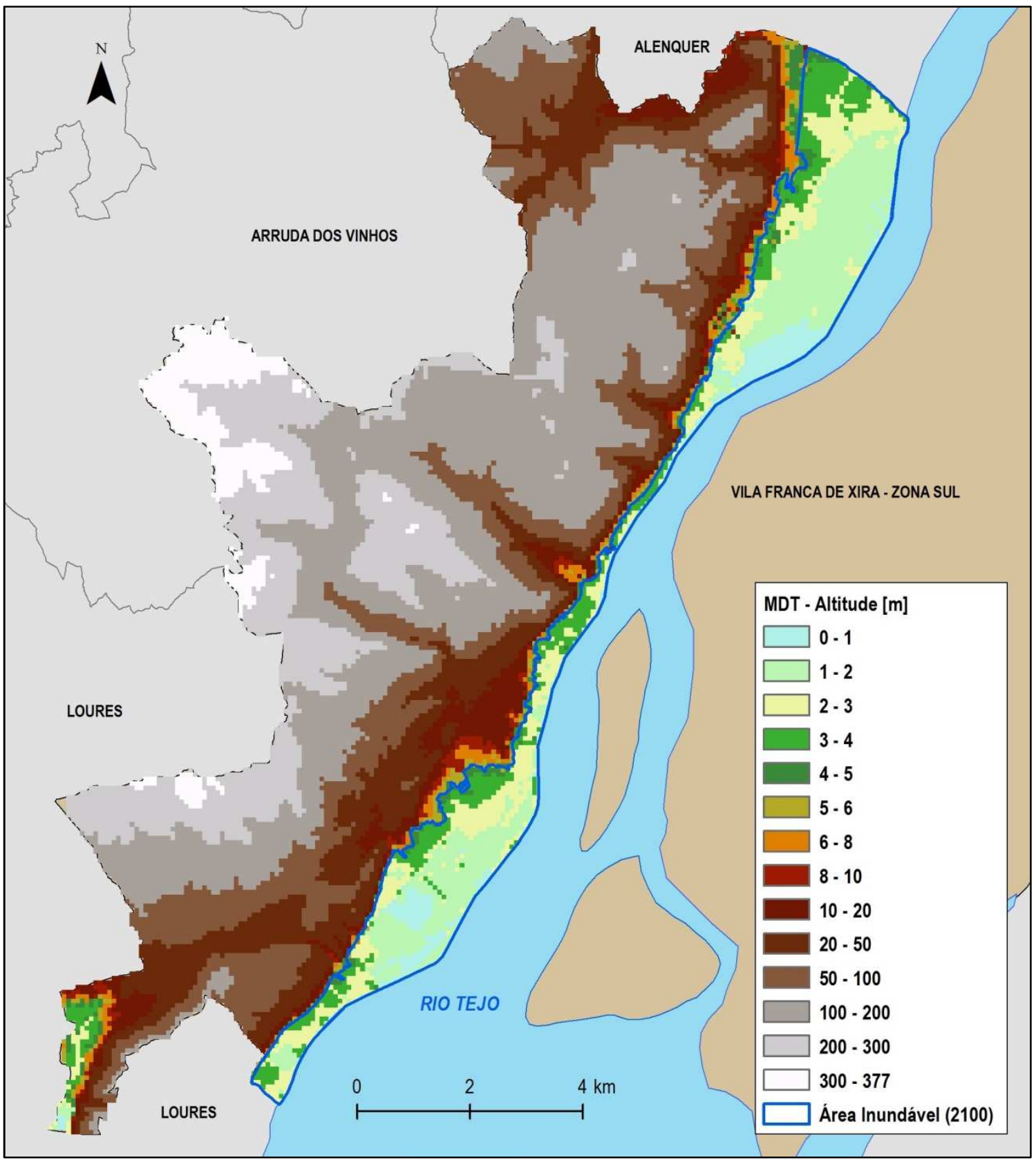

Figura 1 - Modelo Digital do Terreno (MDT) da zona norte do concelho de Vila Franca de Xira e área inundável resultante da simulação

Fonte: elaborado com base nas curvas de nível com equidistância de $1 \mathrm{~m}$, cedidas pela Câmara Municipal de Vila Franca de Xira. 
É de salientar que, de acordo com a Avaliação Ambiental Estratégica do Plano Diretor Municipal do concelho de Vila Franca de Xira, além da suscetibilidade a inundação decorrente de cheias progressivas no rio Tejo, este concelho apresenta também suscetibilidade a cheias rápidas nas pequenas bacias hidrográficas (Instituto Superior Técnico, 2009). Ainda segundo este trabalho, a ocupação atual de áreas inundáveis ${ }^{1}$ no concelho de Vila Franca de Xira - cerca de 5,3\% - é um fator contributivo para o aumento da vulnerabilidade a inundações (Instituto Superior Técnico, 2009).

Com efeito, e com vista a estudar a morfologia do território e aplicar o tipping point de referência $(4,5 \mathrm{~m})$ foi desenvolvido, num primeiro momento, um MDT da zona norte do concelho de Vila Franca de Xira, elaborado a partir das curvas e nível com equidistância de 1 m. O MDT permitiu distinguir uma faixa ribeirinha com altitudes compreendidas entre 0 e 5 $\mathrm{m}$, seguida por uma faixa de transição da planície para o relevo com altitudes entre 6 e $10 \mathrm{~m}$ (Figura 1).

Relativamente à determinação do tipping point, optou-se por fazer a transposição dos cenários do caso de Lisboa para Vila Franca de Xira. I.e., foram assumidos os pressupostos estabelecidos pelo Projeto de Investigação "Estuários e Deltas Urbanizados. Contributos para um Planeamento e Gestão Integrados. O Caso de Lisboa" (2010-2013), considerando-se o risco de inundação como fator crítico de alterações climáticas, com convergência de vários fenómenos: a subida do NMM, as cheias progressivas no Tejo e as cheias repentinas nas pequenas bacias hidrográficas, storm surges e eventos extremos de marés e de ondulação (Figueira de Sousa et al., 2013). Consideram-se também os mesmos cenários de alterações climáticas para o horizonte temporal 2100 que levaram à definição do tipping point de 4,5 m naquele trabalho de investigação. Tal ponto de elevação crítico resultou de combinações de diferentes cenários/projeções de subida do NMM com vários eventos em simultâneo: extremos de maré, extremos de ondulação, cheias e storm surges (Tabela 1).

\begin{tabular}{|c|c|c|c|c|c|c|c|c|}
\hline Cenários de subida do & NMM & Cenários para tipping & Maré & Correção & Ondulação & Cheia & Storm & ถึ้ \\
\hline
\end{tabular}

\footnotetext{
${ }^{1}$ Áreas inundáveis: "ou ameaçadas pelas cheias correspondem às áreas contíguas à margem dos cursos de água, que se estendem até à linha alcançada pela cheia com período de retorno de 100 anos, ou pela maior cheia conhecida no caso em que não existiam dados que permitiam identificar a anterior" (Aviso n.으 20905/2009, de 18 de Novembro). No caso de Vila Franca de Xira, as zonas inundáveis foram delimitadas (num estudo efetuado pelo LNEC - Laboratório Nacional de Engenharia Civil) tendo como referência a cota de cheia de 3,81 metros, correspondente à cheia do Tejo de 1979 (Instituto Superior Técnico, 2009).
} 


\begin{tabular}{|c|c|c|c|c|c|c|c|c|}
\hline $\begin{array}{l}\text { NMM para o horizonte } \\
2100\end{array}$ & & points & & $\begin{array}{l}\text { topográfica } \\
\text { da } \\
\text { cartografia }\end{array}$ & & & surge & \\
\hline Rahmstorf (2007) A1 & \multirow{3}{*}{$+1,00 \mathrm{~m}$} & \multirow{3}{*}{$\begin{array}{c}\begin{array}{c}\text { Melhor cenário } \\
21 \text { eventos de maré / } \\
\text { ano }\end{array} \\
\begin{array}{c}\text { Melhor cenário } \\
4 \text { eventos de maré / } \\
\text { ano }\end{array}\end{array}$} & \multirow{2}{*}{$+2,12 \mathrm{~m}$} & \multirow{15}{*}{$+0,16 \mathrm{~m}$} & \multirow{2}{*}{$+0,40 \mathrm{~m}$} & \multirow{2}{*}{$+0,40 \mathrm{~m}$} & \multirow{2}{*}{$+0,42 \mathrm{~m}$} & \multirow{10}{*}{$\begin{array}{l}+ \\
\stackrel{+}{+} \\
\text { o } \\
3\end{array}$} \\
\hline CCIAM - Portugal (2010) A1 & & & & & & & & \\
\hline $\begin{array}{l}\text { North Carolina AR (2010) } \\
\text { Recomendado }\end{array}$ & & & $+2,22 \mathrm{~m}$ & & $+0,40 \mathrm{~m}$ & $+0,40 \mathrm{~m}$ & $+0,32 \mathrm{~m}$ & \\
\hline Vellinga et al. (2009) & \multirow{3}{*}{$+1,20 \mathrm{~m}$} & \multirow{3}{*}{$\begin{array}{l}\text { Cenário intermediário } \\
21 \text { eventos de maré / } \\
\text { ano }\end{array}$} & \multirow{3}{*}{$+2,12 \mathrm{~m}$} & & \multirow{3}{*}{$+0,40 \mathrm{~m}$} & \multirow{3}{*}{$+0,30 \mathrm{~m}$} & \multirow{3}{*}{$+0,32 \mathrm{~m}$} & \\
\hline Defra (2006) Recomendado & & & & & & & & \\
\hline $\begin{array}{l}\text { Climate Rotterdam (2010) } \\
\text { Pior }\end{array}$ & & & & & & & & \\
\hline Rahmstorf (2010) & \multirow{4}{*}{$+1,40 \mathrm{~m}$} & \multirow{2}{*}{$\begin{array}{c}\text { Cenário intermediário } \\
4 \text { eventos de maré / } \\
\text { ano }\end{array}$} & \multirow{2}{*}{$+2,22 \mathrm{~m}$} & & \multirow{2}{*}{$+0,40 m$} & \multirow{2}{*}{$+0,10 m$} & \multirow{2}{*}{$+0,22 \mathrm{~m}$} & \\
\hline California CATR (2009) A1f1 & & & & & & & & \\
\hline $\begin{array}{l}\text { North Carolina AR (2010) } \\
\text { Pior }\end{array}$ & & \multirow{2}{*}{$\begin{array}{c}\text { Cenário intermediário } \\
62 \text { eventos de maré / } \\
\text { ano }\end{array}$} & \multirow{2}{*}{$+1,92 \mathrm{~m}$} & & \multirow{2}{*}{$+0,40 \mathrm{~m}$} & \multirow{2}{*}{$+0,30 m$} & \multirow{2}{*}{$+0,32 \mathrm{~m}$} & \\
\hline CCIAM - Portugal (2011) & & & & & & & & \\
\hline Hansen (2007) & \multirow{5}{*}{$+2,00 \mathrm{~m}$} & \multirow{5}{*}{$\begin{array}{c}\text { Cenário extremo } \\
\text { ondulação normal } \\
21 \text { eventos de maré / } \\
\text { ano }\end{array}$} & \multirow{5}{*}{$+2,12 \mathrm{~m}$} & & \multirow{5}{*}{$+0,28 \mathrm{~m}$} & \multirow{5}{*}{-} & \multirow{5}{*}{-} & \multirow{5}{*}{$\begin{array}{l}+ \\
\stackrel{+}{+} \\
\text { बू } \\
3\end{array}$} \\
\hline Pfeffer et al. (2008) Extremo & & & & & & & & \\
\hline $\begin{array}{l}\text { Thames Estuary (2009) } \\
\text { Extremo }\end{array}$ & & & & & & & & \\
\hline $\begin{array}{c}\text { Defra, London (2010) } \\
\text { Extremo }\end{array}$ & & & & & & & & \\
\hline UKCIPog Extremo & & & & & & & & \\
\hline
\end{tabular}

Tabela 1 - Cenários de subida do NMM para o ano 2100 e simulação de tipping points para a inundação do Tejo

Fonte: adaptado Figueira de Sousa et al., 2013.

Apresenta-se de seguida a explicação dos valores constantes da Tabela 1, os quais foram considerados no âmbito do projeto de investigação que enquadra o presente artigo:

1. Foram considerados quatro valores para a subida do NMM, com base num conjunto de cenários de subida do NMM, propostos por vários autores para o horizonte 2100: um valor mais otimista, correspondente a uma estimativa de 1,00 m; dois valores intermédios, um correspondente a uma estimativa de 1,20 m e outro a uma estimativa de $1,40 \mathrm{~m}$, valores que definem o intervalo para o qual existe um consenso geral da comunidade científica acerca das projeções de subida do NMM (Rahmstorf, 2010 cit in Figueira de Sousa et al., 2013); um valor extremo, correspondente a uma estimativa de subida do NMM de 2,00 m. 
2. Os valores de subida do NMM foram então combinados com vários eventos máximos de maré (preia-mar) e respetiva frequência anual, com base na tabela de marés do ano 2011 da Administração do Porto de Lisboa: 62 eventos de 4,00 m, 21 eventos de 4,20 m e 4 eventos máximos de 4,30 m. Estes foram comparados com os máximos para o período de referência 2000-2010, calculados pelo Modelo de Previsão de Marés Astronómicas da FCUL, que variam entre 4,26 m e 4,50 m (Figueira de Sousa et al., 2013). Dado que o zero hidrográfico de referência está situado 2,08 m abaixo do NMM em Cascais foi necessário aplicar aquela correção, obtendo-se respetivamente: 62 eventos de 1,92 m, 21 eventos de 2,12 m e 4 eventos máximos de 2,22 m em 2011. Por outro lado, dado que o zero hidrográfico foi definido em relação ao NMM adotado em 1938, existe atualmente uma diferença sistemática entre as alturas da água observadas em relação ao NMM em Cascais e as alturas estimadas da maré. Segundo dados mais recentes de Antunes (2011), a diferença é de +0,159 m (Figueira de Sousa et al., 2013). Aquele valor, designado por correção topográfica da cartografia, também tem de ser aplicado à altura da maré para que a sua altura fique definida em relação ao zero da cartografia terrestre (NMM em Cascais).

3. Aos cenários de subida do NMM e de marés foi adicionado o fator ondulação, cuja "estimativa no banco norte do Tejo é o elemento mais inconsistente dos dados de projeção" (Figueira de Sousa et al., 2013). Segundo Dias e Santos (2013), tal decorre do facto de a margem norte do Tejo ser em grande parte artificializada e a ondulação no estuário, que depende principalmente das interações do vento com a superfície da água, não ter um impacte significativo, pelo que não há muitos estudos sobre este assunto. Segundo os mesmos autores, a ondulação de maior magnitude ocorre na margem sul, entre Alcochete e o Alfeite e a maior agitação ocorre no interior do estuário. No caso da margem norte, a amplitude da ondulação tem probabilidade de ser maior quando a direção do vento está entre os quadrantes este e sudoeste (Dias e Santos, 2013). Assim, com base nos dados disponíveis para o Alfeite e o interior do estuário, "considera-se o valor de 0,40 m para uma onda frequente e 0,80 m como valor extremo", ainda que "para efeitos de subida do 
NMM, apenas o aumento da onda em metade daqueles valores deve ser considerado" (Figueira de Sousa et al., 2013).

4. Foi ainda considerado o efeito das cheias rápidas e das cheias progressivas. Para determinar os atuais efeitos das cheias progressivas do Tejo, a Administração da Região Hidrográfica do Tejo (ARH-Tejo) adotou o valor de referência de 0,15 m, calculado pelo LNEC para as áreas do Rio Trancão (Figueira de Sousa et al., 2013), a jusante de Vila Franca de Xira.

5. Foi ainda tido em conta o efeito de storm surges. Segundo Santos e Cruz (2010), o valor 0,42 m corresponde ao máximo storm surge registado no período 2000-2010 no marégrafo de Cascais (Figueira de Sousa et al., 2013). Por outro lado, Santos e Miranda (2006), apresentam as estimativas de $0,40 \mathrm{~m}, 0,44 \mathrm{~m}, 0,50 \mathrm{~m}$ e 0,58 $\mathrm{m}$ para períodos de retorno ${ }^{2}$ de 5, 10, 25, 50 e 100 anos, respetivamente (Figueira de Sousa et al., 2013). Segundo a ARH-Tejo (2009), dados de 1978 e 1981 apontam para eventos máximos de 0,42 $\mathrm{m}$ e 0,52 $\mathrm{m}$, respetivamente. No entanto, ao valor de 0,52 m em Cascais, corresponde um valor de 0,48 m em Lisboa (Dias e Santos, 2013). Para fins de análise do uso do solo na frente ribeirinha, a ARH-Tejo utilizou o valor de 0,5 m como referência para um período de retorno de 100 anos (Figueira de Sousa et al., 2013).

Daquelas combinações de 5 variáveis resultaram quatro tipping points de 4,50 m e um tipping point de 4,56 m para o pior cenário, que constituem cenários para a probabilidade da cota atingida por inundações considerando o horizonte temporal 2100. No desenvolvimento do Projeto de Investigação "Estuários e Deltas Urbanizados. Contributos para um Planeamento e Gestão Integrados. O Caso de Lisboa" foram testados três tipping points estabelecidos na cartografia terrestre: 4,00 m, 4,50 m e 5,00 m. Segundo Figueira de Sousa et al. (2013), dado o conhecimento científico existente acerca do efeito dos GEE e das projeções da subida do NMM e atendendo ao princípio da precaução, foi considerado razoável assumir o tipping point de 4,50 m como referência para o planeamento urbano em Lisboa até 2100.

\footnotetext{
${ }^{2}$ Correspondem à probabilidade de ocorrência de dois eventos sucessivos de storm surge, de igual magnitude, expressa em intervalos de tempo.
} 
Dada a incerteza inerente aos cenários de subida do NMM e às diferenças entre os valores apresentados por diversos autores com base em diferentes modelos (e.g. divergência dos valores obtidos por modelos geofísicos e semi-empíricos) bem como a incerteza nos valores adotados por Figueira de Sousa, et al. (2013) para os vários eventos extremos considerados, optou-se por adotar os mesmos valores e o tipping point de 4,5 $\mathrm{m}$ para efetuar uma simulação em Vila Franca de Xira, assumindo-se que, dada a proximidade dos territórios e as vulnerabilidades comuns, tal não introduz um erro significativo.

Ainda assim, há que ter presente que o efeito das cheias progressivas do Tejo e das cheias rápidas das pequenas bacias hidrográficas não será o mesmo nos dois concelhos, bem como, o efeito dos extremos de ondulação e storm surges, visto o concelho de Vila Franca de Xira estar situado no interior do estuário.

Adotado o tipping point de 4,5 m, efetuou-se a simulação da subida do NMM suportada no $M D T$, que resultou na delimitação de uma área inundável ${ }^{3}$ (indicada nas figuras como "Área Inundável (2100)") com uma superfície de aproximadamente $20,38 \mathrm{~km}^{2}$, o que corresponde a 6,4\% da área total do concelho de Vila Franca de Xira (Figuras 1 a 5). Partindo daquela simulação foram então avaliados os impactes da subida do NMM sobre a população residente, o edificado e as principais infraestruturas de transporte. Para tal procedeu-se ao tratamento e análise de dados cartográficos e de dados estatísticos com recurso a Sistema de Informação Geográfica (SIG), nomeadamente, software ArcGIS (módulos ArcMap e Arc(atalog). A Tabela 2 apresenta os dados utilizados e respetivas fontes.

\begin{tabular}{|c|c|}
\hline Dados & Fontes \\
\hline $\begin{array}{c}\text { Censos } 2011 \text { (BGRI - Base Geográfica de Referenciação de } \\
\text { Informação; Ficheiro de Síntese) }\end{array}$ & INE - Instituto Nacional de Estatística \\
\hline CAOP - Carta Administrativa Oficial de Portugal 2012.1 & Direção Geral do Território \\
\hline Cartografia à escala 1:5000, 2003 & Câmara Municipal de Vila Franca de Xira \\
\hline Altimetria $1 \mathrm{~m}$ & Câmara Municipal de Vila Franca de Xira \\
\hline Rede viária & OpenStreetMap \\
\hline
\end{tabular}

Tabela 2 - Dados utilizados na avaliação de impactes da subida do NMM em Vila Franca de Xira.

\footnotetext{
${ }^{3}$ No contexto da simulação da subida do NMM efetuada, define-se "área inundável" como a área em risco de inundação devido à subida do NMM, combinada com outros eventos (i.e. marés, ondulação, precipitação e storm surge), e delimitada tendo como referência a cota de 4,5 m, correspondente ao tipping point considerado na simulação da inundação do Tejo.
} 


\subsection{Avaliação dos impactes potenciais da subida do NMM}

Com base na simulação e nos dados censitários de 2011 procurou-se estimar os impactes da subida do NMM sobre a população residente nas subsecções estatísticas que se sobrepõem total ou parcialmente à área em risco de inundação (Figura 2). No caso das subsecções estatísticas cuja área é apenas parcialmente inundável, assumiu-se como pressuposto uma distribuição homogénea da população naquelas subsecções, fazendo-se equivaler o número de indivíduos afetados à proporção de área inundável.

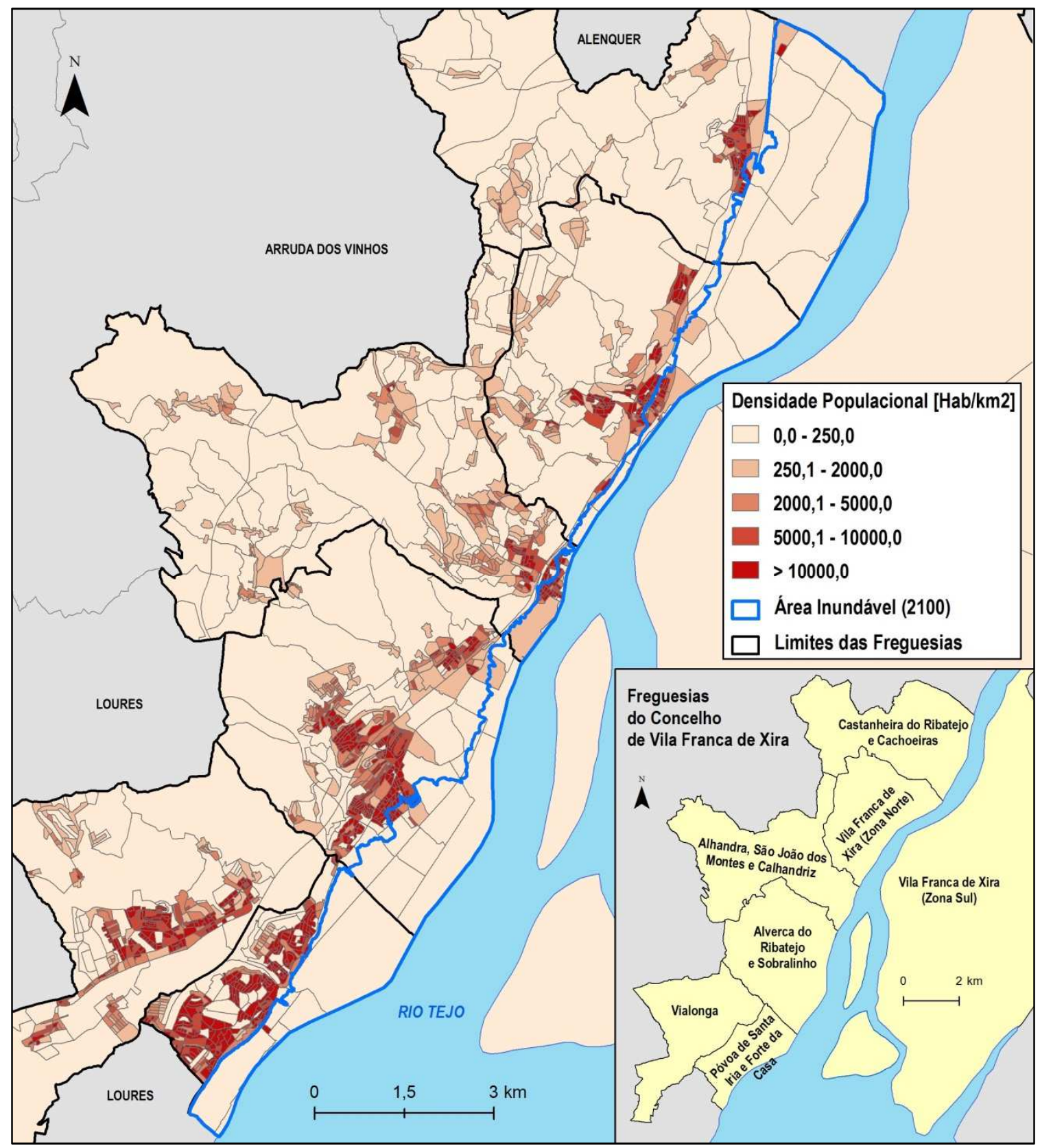

Figura 2 - Densidade populacional e subseções estatísticas localizadas na área inundável Fonte: elaborado com base em informação estatística de INE, Censos 2011. 
Com efeito, estima-se que cerca de 7.843 indivíduos residam atualmente na área inundável. Verifica-se igualmente que várias subsecções estatísticas total ou parcialmente inundáveis concentram mais de 125 indivíduos. É por exemplo, o caso de várias subseções estatísticas com densidade populacional superior a $10.000 \mathrm{hab} / \mathrm{km}^{2}$, localizadas no centro de Alhandra e na cidade de Vila Franca de Xira, onde a inundação teria um impacte considerável (Figura 2).

Com base na simulação efetuada e em dados disponíveis na cartografia à escala 1:5.000, estimaram-se os impactes da subida do NMM sobre o edificado atualmente existente e que se localiza na área inundável. Concluiu-se que 5.507 edifícios poderão estar expostos a inundações. A função dos edifícios foi aferida utilizando a codificação associada aos elementos cartográficos e descrita no catálogo de objetos da cartografia 1:5000 ${ }^{4}$. Considerou-se assim as seguintes funções: habitação; administração e serviços públicos; educação; apoio social; saúde; defesa, segurança e protecção civil; indústria e armazenagem; cultura; desporto; comércio (Figuras 3 e 4).

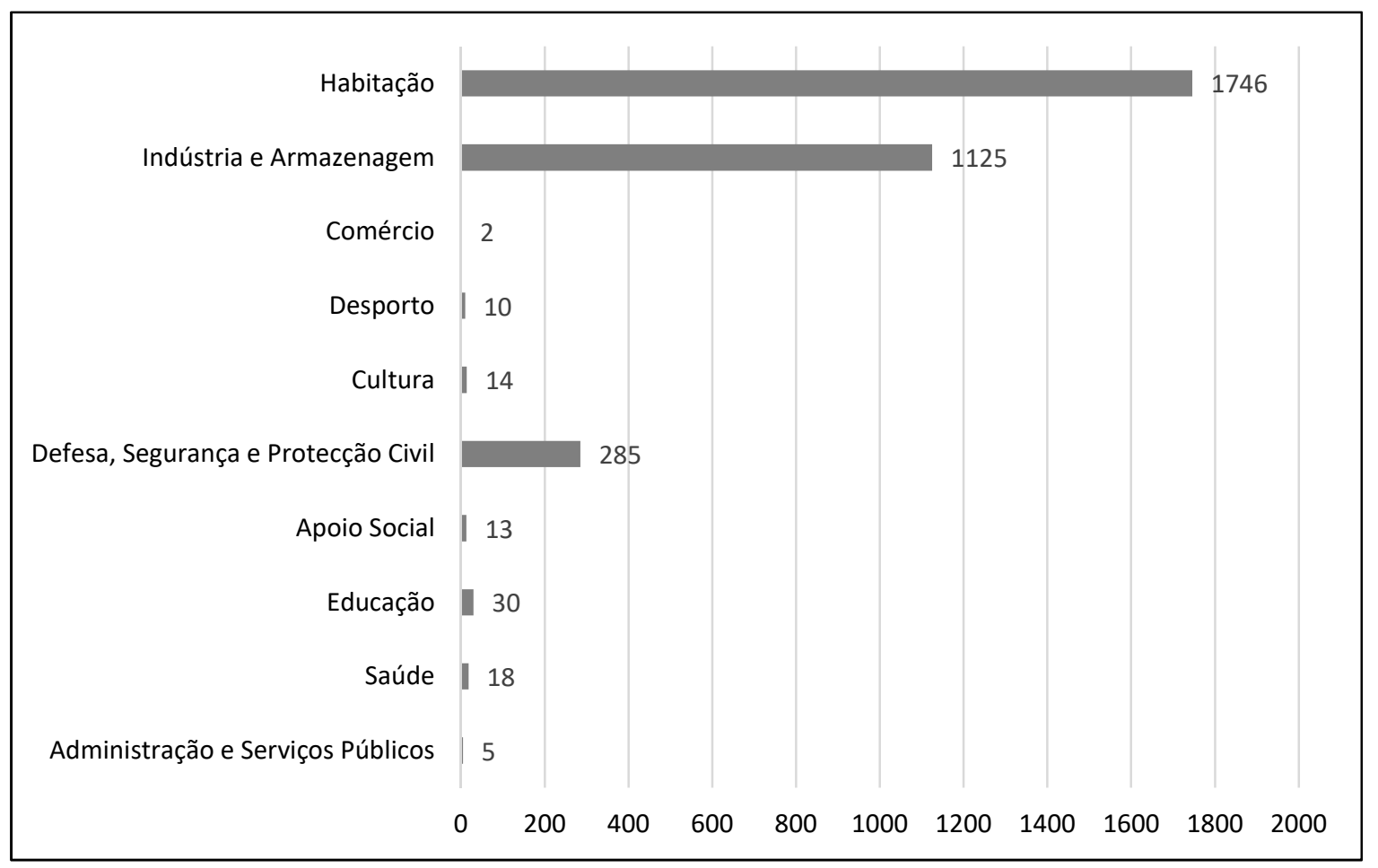

Figura 3 - Número de edifícios localizados na área inundável, de acordo com a sua função

\footnotetext{
${ }^{4}$ Um reconhecimento de campo efetuado na cidade de Vila Franca de Xira permitiu confirmar a função constante da cartografia para alguns edifícios naquela área.
} 
Dos 5.507 edifícios localizados na área inundável, estima-se que 1.746 estejam afetos a habitação, 1.125 afetos a indústria e armazenagem e 285 afetos a defesa, segurança ou proteção civil, sendo aquelas três funções as que apresentam maior número de edifícios em risco de inundação (Figuras 3 a 7).
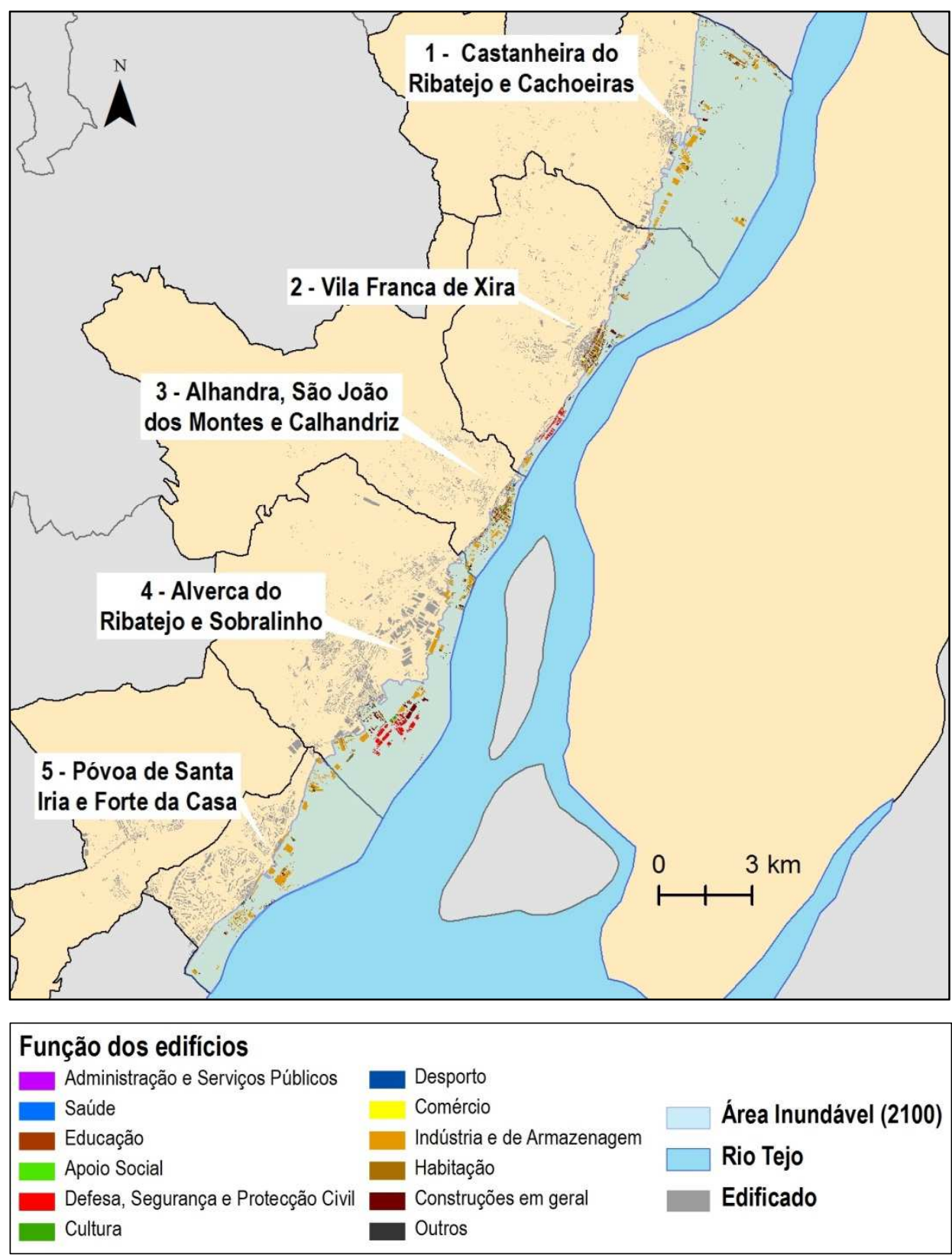

Figura 4 - Edifícios localizados na área inundável de acordo com a sua função Fonte: elaborado com base no edificado existente na Cartografia à Escala 1:5.000, 2003.

Verifica-se ainda que os edifícios de administração e serviços públicos localizados na área inundável pertencem à cidade de Vila Franca de Xira, nomeadamente os edifícios correspondentes ao Tribunal, Câmara Municipal e correios (Figura 5). 

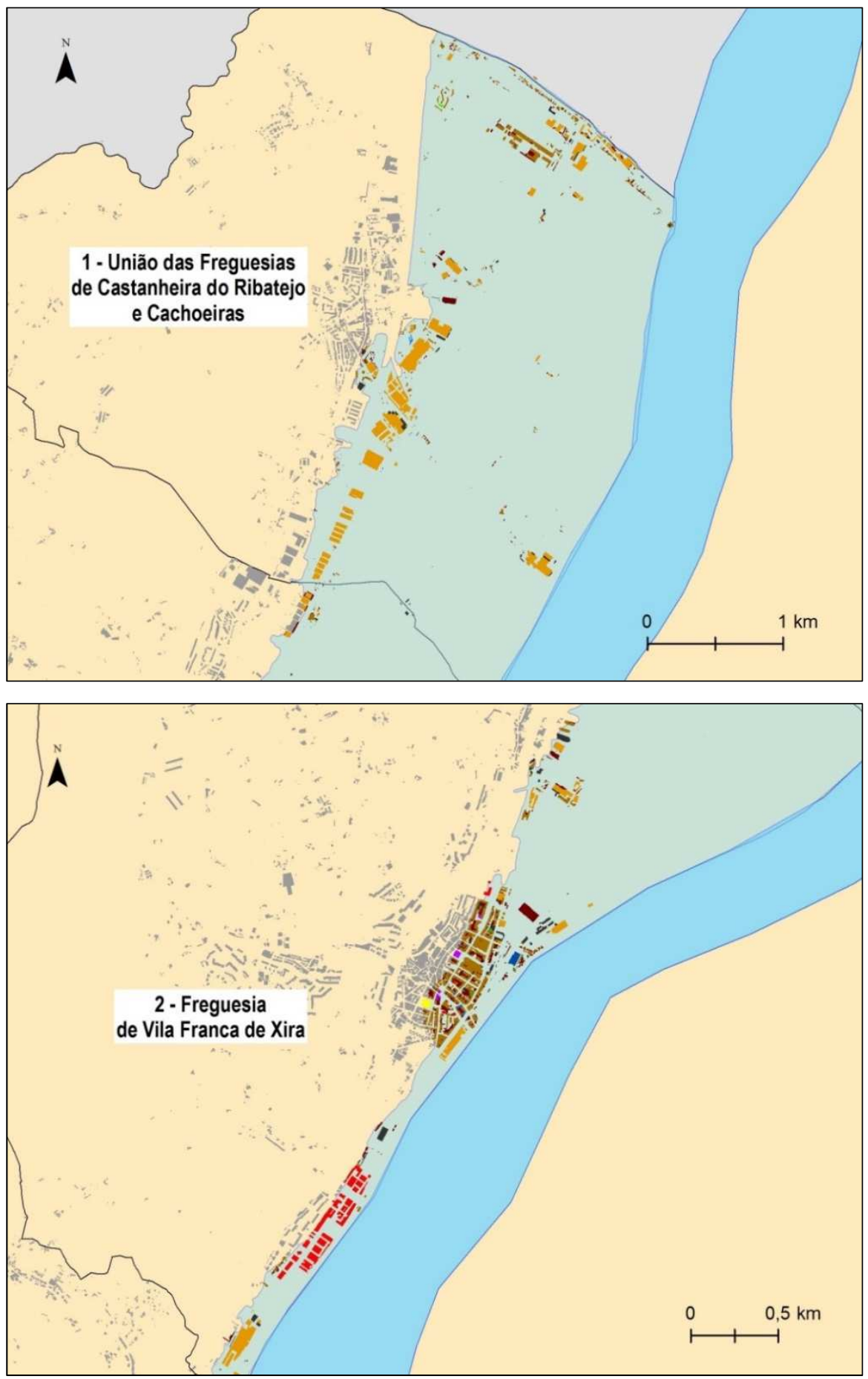

\begin{tabular}{|lll|}
\hline Função dos edifícios & & \\
Administração e Serviços Públicos & Desporto & \\
Saúde & Comércio & \\
Educação & Indústria e de Armazenagem & Área Inundável (2100) \\
Apoio Social & Habitação & Rio Tejo \\
Defesa, Segurança e Protecção Civil & Construções em geral & Edificado \\
Cultura & Outros & \\
\hline
\end{tabular}

Figura 5 - Edifícios localizados na área inundável, de acordo com a sua função, por freguesia: União das Freguesias de Castanheira do Ribatejo e Cachoeiras e Freguesia de Vila Franca de Xira Fonte: elaborado com base no edificado existente na Cartografia à Escala 1:5.000, 2003. 

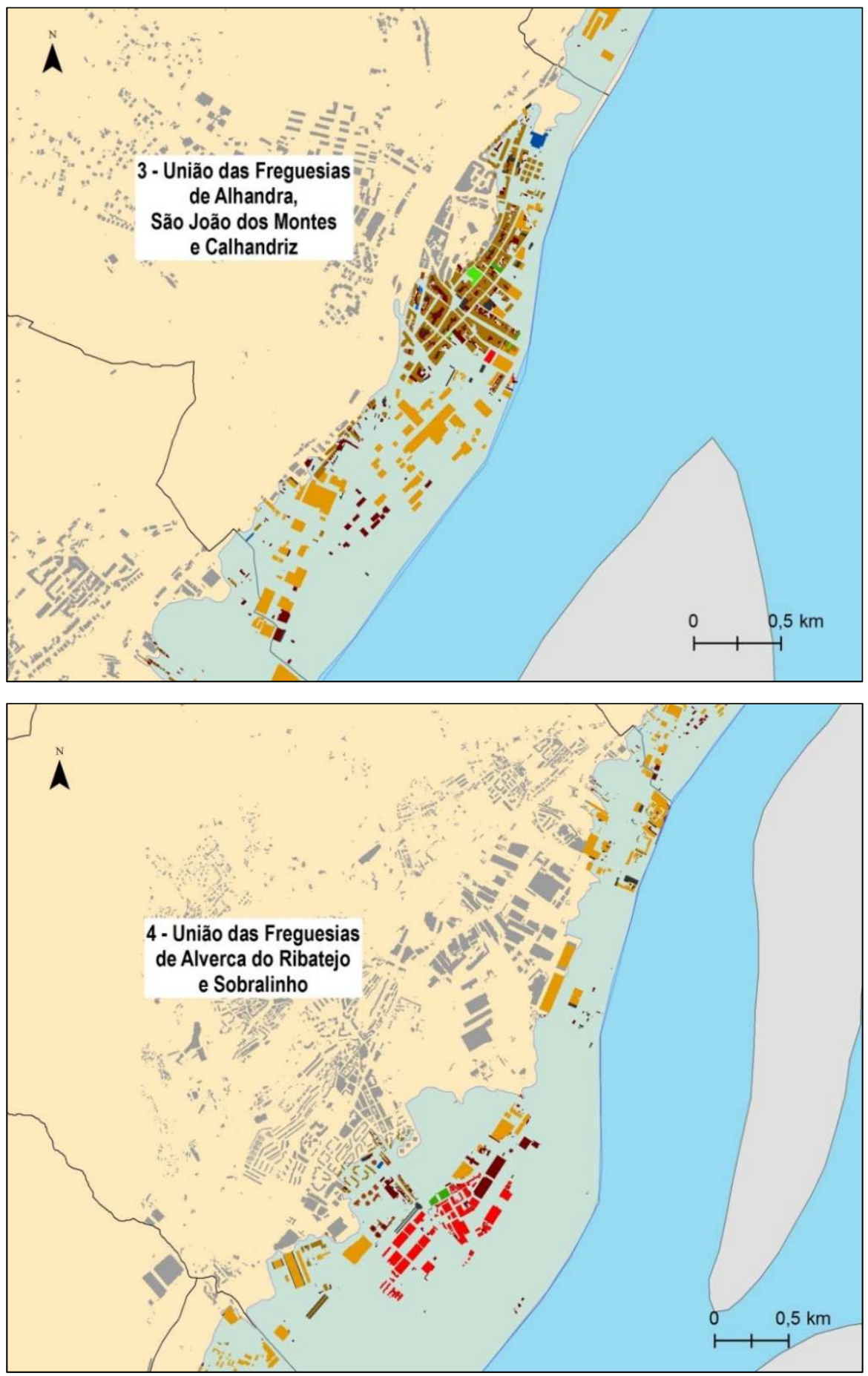

\begin{tabular}{|lll|}
\hline Função dos edificios & & \\
Administração e Serviços Públicos & Desporto & \\
Saúde & Comércio & Área Inundável (2100) \\
Educação & Indústria e de Armazenagem & Rio Tejo \\
Apoio Social & Habitação & Rejo \\
Defesa, Segurança e Protecção Civil & Construções em geral & Edificado \\
Cultura & Outros & \\
\hline
\end{tabular}

Figura 6 - Edifícios localizados na área inundável, de acordo com a sua função, por freguesia: União das Freguesias de Alhandra, São João dos Montes e Calhandriz e União das Freguesias de Alverca do Ribatejo e Sobralinho

Fonte: elaborado com base no edificado existente na Cartografia à Escala 1:5.000, 2003. 


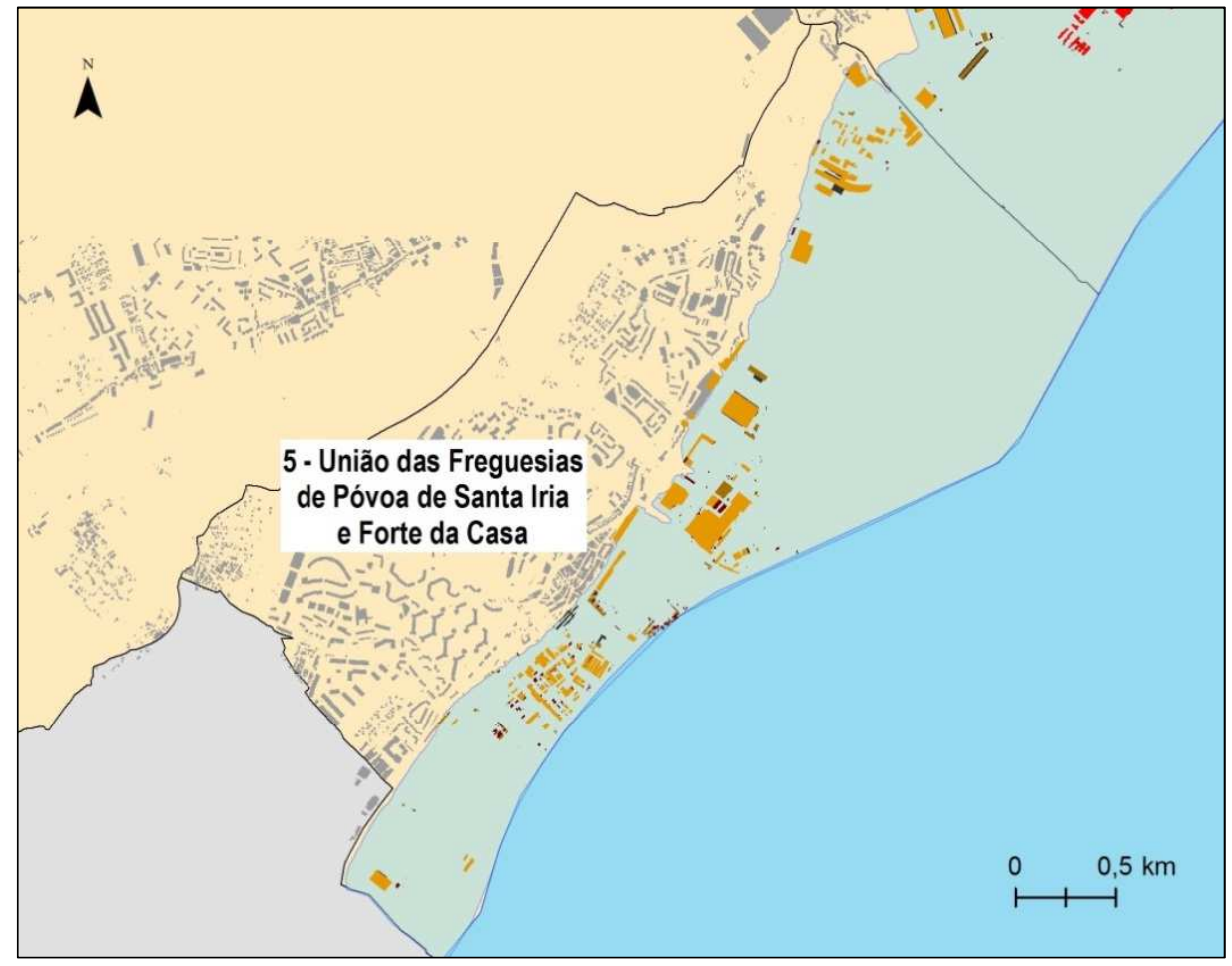

\begin{tabular}{|lll|}
\hline Função dos edifícios & & \\
Administração e Serviços Públicos & Desporto & \\
Saúde & Comércio & Área Inundável (2100) \\
Educação & Indústria e de Armazenagem & Rio Tejo \\
Apoio Social & Habitação & Rejo \\
Defesa, Segurança e Protecção Civil & Construções em geral & Edificado \\
Cultura & Outros & \\
\hline
\end{tabular}

Figura 7 - Edifícios localizados na área inundável, de acordo com a sua função, por freguesia: União das Freguesias de Póvoa de Santa Iria e Forte da Casa

Fonte: elaborado com base no edificado existente na Cartografia à Escala 1:5.000, 2003.

Por fim, procedeu-se à análise dos impactes da subida do NMM sobre as infraestruturas de transporte que servem o concelho de Vila Franca de Xira, mais precisamente sobre a rede rodoviária e ferroviária.

No que se refere à rede rodoviária, constata-se que a autoestrada A1/IP1 e as estradas nacionais EN1, EN1-3 e EN10 correspondem às principais infraestruturas inundáveis: a A1/IP1 em cerca de 3,1 km (principalmente num troço que atravessa Castanheira do Ribatejo, situado a sul do nó de Vila Franca de Xira); a EN1 em cerca de 0,5 km (em Vila Franca de Xira); a EN1-3 em cerca de 1,6 km (em Castanheira do Ribatejo); a EN10 em cerca 
de $1,6 \mathrm{~km}$ (em Vila Franca de Xira, destacando-se o troço de acesso à Ponte Marechal Carmona e o troço entre a Escola da Armada e Alhandra - Figura 8).

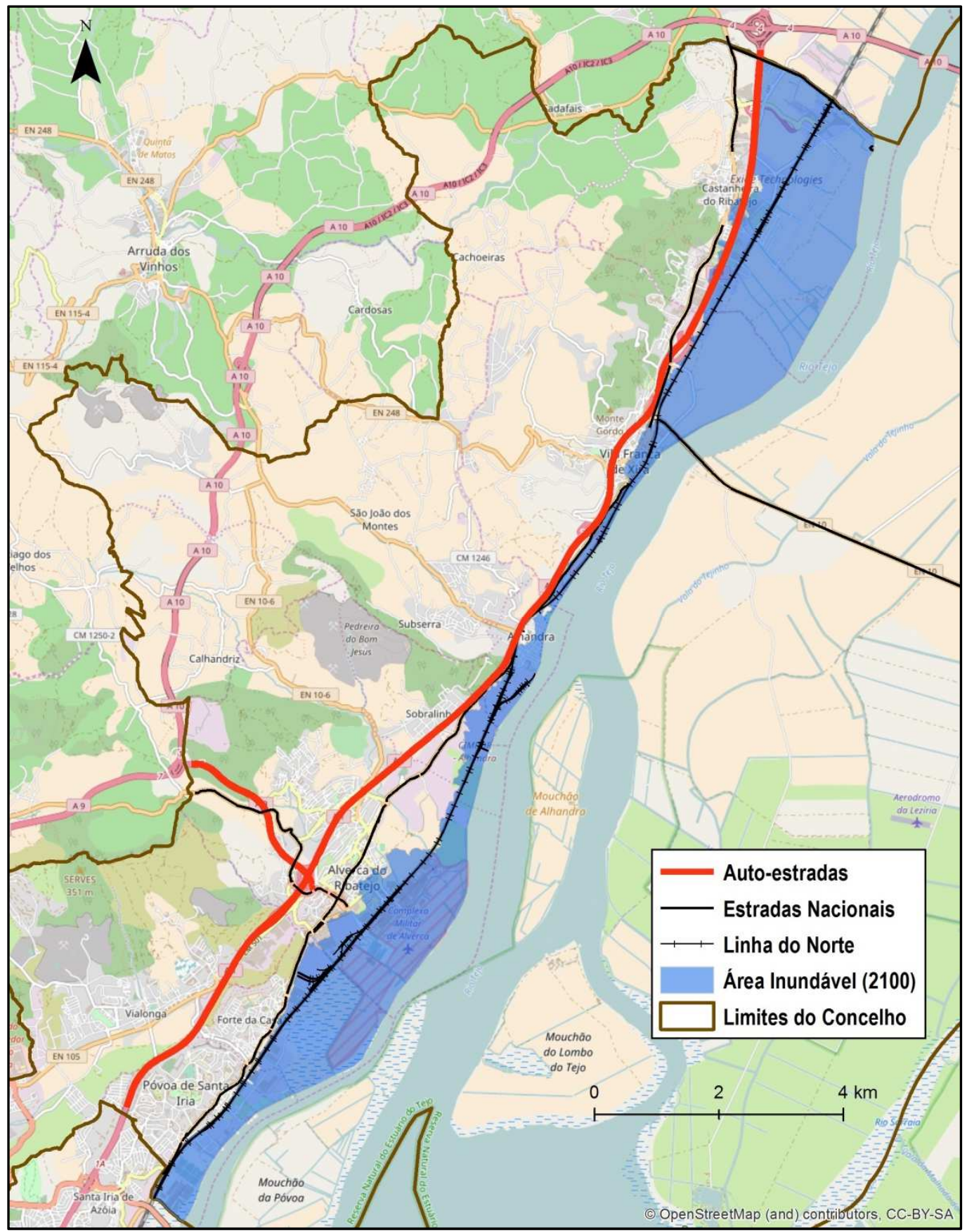

Figura 8 - Efeitos sobre as infraestruturas rodoviárias e ferroviárias no concelho de Vila Franca de Xira 
No que se refere à rede ferroviária, mais precisamente à Linha do Norte, a simulação efetuada permite constatar que esta infraestrutura seria substancialmente afetada, passível de submersão em quase toda a extensão com implantação no concelho de Vila Franca de Xira. Algo que ganha particular acuidade pelo facto de a Linha do Norte assumir grande relevância no contexto nacional, uma vez que assegura vários serviços de transporte ferroviário (passageiros e mercadorias), com destaque para as ligações ao longo do corredor Lisboa-Coimbra-Porto-Braga.

\section{Considerações finais}

O concelho de Vila Franca de Xira é um território onde estão implantados vários aglomerados populacionais, edifícios e infraestruturas, com destaque para edifícios de habitação e edifícios afetos a comércio e serviços, instalações industriais, a Linha do Norte e eixos rodoviários importantes no acesso à cidade de Lisboa, ao norte e ao sul do país.

É igualmente sabido que o concelho é vulnerável a cheias rápidas nas pequenas bacias hidrográficas e a cheias progressivas no rio Tejo e que existem edifícios e infraestruturas em áreas ameaçadas pelas cheias na sua frente ribeirinha (Instituto Superior Técnico, 2009). No entanto, o fenómeno das alterações climáticas vem contribuir para o aumento das vulnerabilidades atuais e criar novos fatores de risco.

Concretizando, a subida do NMM projetada nas técnicas de modelação exacerba o risco de inundações costeiras, submersão permanente, cheias rápidas e progressivas, tanto mais quando combinada com extremos de maré alta e fenómenos de natureza climática como precipitação forte, ondulação forte e storm surges, apontando assim para o futuro aparecimento de novas áreas inundáveis.

A simulação da subida do NMM no concelho de Vila Franca de Xira até ao tipping point de 4,5 m, valor resultante da abordagem what if adotada e dos cenários considerados, permitiu identificar uma área inundável com uma superfície de aproximadamente $20,38 \mathrm{~km}^{2}$. A avaliação de impactes sobre a população residente e o edificado permitiu estimar que atualmente residem 7.843 indivíduos e existem 5.507 edifícios naquela área inundável. No 
que concerne às principais infraestruturas rodoviárias com troços localizados na área calculada, destaca-se a autoestrada A1/IP1 e as estradas nacionais EN1, EN1-3 e EN10. No que diz respeito à rede ferroviária, mais precisamente à Linha do Norte, a simulação efetuada permite constatar que numa situação de inundação até à cota dos $4,5 \mathrm{~m}$, aquela infraestrutura ficaria submersa em quase toda a sua extensão com implantação no concelho de Vila Franca de Xira.

A simulação da subida do NMM em conjunto com a avaliação preliminar de impactes, permitiu assim identificar vulnerabilidades significativas no edificado e nas infraestruturas de transporte que resultariam em danos nos edifícios e infraestruturas, perda de bens, cortes de estradas e interrupção da circulação ferroviária. Algo que torna evidente a necessidade de definição de uma estratégia efetiva de adaptação e a implementação de um conjunto de medidas de adaptação para a área de estudo.

É de notar que atualmente já estão em curso estratégias de adaptação às alterações climáticas, tanto à escala europeia, como à escala nacional. No entanto, os processos de adaptação nos contextos regional e local ainda carecem de desenvolvimento.

Considera-se que vulnerabilidades futuras deverão ser tidas em conta aquando da revisão dos instrumentos de gestão territorial de abrangência regional e municipal, no sentido de diminuir os impactes físicos, económicos e sociais das alterações climáticas.

Neste sentido, a definição de uma estratégia municipal de adaptação às alterações climáticas revela-se de grande oportunidade, devendo articular-se com as estratégias de adaptação às alterações climáticas em curso à escala europeia e nacional, as quais dão o suporte em termos de conhecimento acerca das alterações climáticas e das orientações de base para a definição da estratégia municipal.

Relativamente a medidas de adaptação às alterações climáticas, existem diversas opções de adaptação a inundações, adequadas para zonas estuarinas. Destaca-se a título de exemplo: um planeamento e ordenamento do território que potencie a redução do risco de inundação, a utilização de infraestruturas de proteção contra inundação, a criação de sistemas de previsão e alerta de inundações, a elaboração de planos de evacuação de 
contingências, a melhoria dos regulamentos de construção e a criação de seguros baseados no risco.

Ainda no que se refere às medidas de adaptação, importa notar que, perante a incerteza climática, a incerteza na transposição dos cenários globais para um nível local e a imperfeição dos modelos de avaliação de impactes e vulnerabilidades, considera-se ser uma boa política a opção por medidas de adaptação que se traduzam na redução do risco para pessoas e bens, mesmo que as alterações climáticas que venham a ocorrer não se traduzam numa subida do NMM que corresponda exatamente às projeções efetuadas.

\section{Agradecimentos}

Este trabalho tem por base os resultados da Dissertação de Mestrado "Os Estuários e as Alterações Climáticas: Impactes da Subida do Nível Médio das Águas do Mar em Vila Franca de Xira", desenvolvida em articulação com o Projeto de Investigação "Estuários e Deltas Urbanizados. Contributos para um Planeamento e Gestão Integrados. O Caso de Lisboa" (2010-2013). Beneficiou ainda da investigação desenvolvida, por um dos autores, no âmbito de uma Bolsa de Pós-Doutoramento financiada pela Fundação para a Ciência e Tecnologia (SFRH/BPD/110975/2015).

\section{Referências bibliográficas}

ANTUNES, C. Análise da evolução do nível médio do mar em Cascais. Lisboa: Agência Portuguesa do Ambiente, I. P./Administração da Região Hidrográfica do Tejo, I. P., Lisboa, 2013.

ANTUNES, C.; SILVEIRA, T.; ANDRADE, C.; TABORDA, R. Cenários de evolução do nível médio do mar para 2100. Lisboa: Agência Portuguesa do Ambiente, I. P./Administração da Região Hidrográfica do Tejo, I. P., Lisboa, 2013.

Aviso n.o 20905/2009 (Município de Vila Franca de Xira). “Diário da República 2.a Série”, 224 (2009-11-18) 46972.

CHURCH, J. A.; CLARK, P. U.; CAZENAVE, A.; GREGORY, J. M.; JEVREJEVA, S.; LEVERMANN, A.; MERRIFIELD, M. A.; MILNE, G. A., NEREM, R. S.; NUNN, P. D.; PAYNE, A. J.; PFEFFER, W. T.; STAMMER, D.; UNNIKRISHNAN, A. S. Sea Level Change. In STOCKER, T. F.; QIN, D.; PLATTNER, G.-K.; TIGNOR, M.; ALLEN, S. K.; BOSCHUNG, J.; 
NAUELS, A.; XIA, Y.; BEX, V.; MIDGLEY, P.M. (Eds.). Climate Change 2013: The Physical Science Basis. Contribution of Working Group I to the Fifth Assessment Report of the Intergovernmental Panel on Climate Change. Cambridge, United Kingdom and New York, NY, USA: Cambridge University Press, 2013.

DIAS, L.; SANTOS, F. D. Climate change scenarios, Lisbon and the Tagus Estuary. In COSTA, J. P.; FIGUEIRA DE SOUSA, J. (Eds.) Climate Change Adaptation in Urbanised Estuaries: Contributes to the Lisbon Case. Lisbon: Faculdade de Ciências Sociais e Humanas - Universidade Nova de Lisboa, 2013, p. 157-173.

FERNANDES, A. Dinâmicas de Revitalização de Frentes Ribeirinhas no Período Pós-Industrial: o Arco Ribeirinho Sul do Estuário do Tejo. Tese de Doutoramento, Faculdade de Ciências Sociais e Humanas - Universidade Nova de Lisboa, 2014.

FIGUEIRA DE SOUSA, J.; GALIAU, S.; VICENTE, T.; OCHOA, R. Lisbon riverfront climate change impacts: buildings, public space, infrastructures, transports and accessibilities, monuments and public art. In COSTA, J. P.; FIGUEIRA DE SOUSA, J. (Eds.) Climate Change Adaptation in Urbanised Estuaries: Contributes to the Lisbon Case. Lisbon: Faculdade de Ciências Sociais e Humanas - Universidade Nova de Lisboa, 2013, p. 177-211.

IPCC. Summary for Policymakers. In STOCKER, T. F.; QIN, D.; PLATTNER, G.-K.; TIGNOR, M.; ALLEN, S. K.; BOSCHUNG, J.; NAUELS, A.; XIA, Y.; BEX, V.; MIDGLEY, P.M. (Eds.). Climate Change 2013: The Physical Science Basis. Contribution of Working Group I to the Fifth Assessment Report of the Intergovernmental Panel on Climate Change. Cambridge, United Kingdom and New York, NY, USA: Cambridge University Press, 2013.

Instituto Superior Técnico. Relatório Ambiental da Avaliação Ambiental Estratégica do Plano Diretor Municipal de Vila Franca de Xira. Vila Franca de Xira: Câmara Municipal de Vila Franca de Xira, 2009.

JEVREJEVA, S.; MOORE, J.C.; GRINSTED, A. Sea level projections to AD2500 with a new generation of climate change scenarios. Global and Planetary Change, 80-81, 2012, p. 14-20, doi:10.1016/j.gloplacha.2011.09.006.

MENDES, C.; OLIVEIRA, D. Climate change and territorial impacts scenarios, the waterfronts. In COSTA, J. P.; FIGUEIRA DE SOUSA, J. (Eds.) Climate Change Adaptation in Urbanised Estuaries: Contributes to the Lisbon Case. Lisbon: Faculdade de Ciências Sociais e Humanas - Universidade Nova de Lisboa, 2013, p. 55-75.

RAHMSTORF, S. A new view on sea level rise. Nature Reports Climate Change. Macmillan Publishers Limited, April 2010, 4, p. 44-45, ISSN 1753-9315.

SANTOS, F. D. Climate change perspectives, the waterfronts. In COSTA, J. P.; FIGUEIRA DE SOUSA, J. (Eds.) Climate Change Adaptation in Urbanised Estuaries: Contributes to the Lisbon Case. Lisbon: Faculdade de Ciências Sociais e Humanas - Universidade Nova de Lisboa, 2013, p. 23-51.

SANTOS, F. D.; FORBES, K.; MOITA, R. (Eds.) Mudança Climática em Portugal, Cenários, Impactes e Medidas de Adaptação - SIAM, Sumário Executivo e Conclusões. Lisboa: Gradiva. 2001.

VERMEER, M.; RAHMSTORF, S. Global sea level linked to global temperature. Proceedings of the National Academy of Sciences of the United States of America. William C. Clark, Harvard University, Cambridge, MA. December 2009, vol. 106, no. 51, p. 21527-21532, DOI 10.1073/pnas.0907765106.

WMO. WMO statement of the status of global climate in 2015. WMO-No. 1167. Geneva: World Meteorological Organization, 2016, ISBN 978-92-63-11167-8. 